\title{
Complications following pediatric cranioplasty after decompressive craniectomy: a multicenter retrospective study
}

\author{
Brandon G. Rocque, MD, MS, ${ }^{1}$ Bonita S. Agee, PhD, ${ }^{1}$ Eric M. Thompson, MD, ${ }^{2}$ Mark Piedra, MD, ${ }^{3}$ \\ Lissa C. Baird, MD, ${ }^{4}$ Nathan R. Selden, MD, PhD, ${ }^{4}$ Stephanie Greene, MD, ${ }^{5}$ \\ Christopher P. Deibert, MD, ${ }^{6}$ Todd C. Hankinson, MD, MBA, ${ }^{7}$ Sean M. Lew, MD, ${ }^{8}$ \\ Bermans J. Iskandar, MD, ${ }^{9}$ Taryn M. Bragg, MD, ${ }^{10}$ David Frim, MD, PhD, ${ }^{11}$ Gerald Grant, MD, ${ }^{12}$ \\ Nalin Gupta, MD, PhD, ${ }^{13}$ Kurtis I. Auguste, MD, ${ }^{13}$ Dimitrios C. Nikas, MD, ${ }^{14}$ \\ Michael Vassilyadi, MD, CM, MSc, ${ }^{15}$ Carrie R. Muh, MD, MS,${ }^{2}$ Nicholas M. Wetjen, MD, ${ }^{16}$ and \\ Sandi K. Lam, MD ${ }^{17}$
}

'Department of Neurosurgery, University of Alabama at Birmingham, Birmingham, Alabama; ${ }^{2}$ Department of Neurosurgery, Duke University, Durham, North Carolina; ${ }^{3}$ Department of Neurosurgery, Billings Clinic, Billings, Montana; ${ }^{4}$ Department of Neurosurgery, Oregon Health Sciences University, Portland, Oregon; ${ }^{5}$ Department of Neurosurgery, University of Pittsburgh,

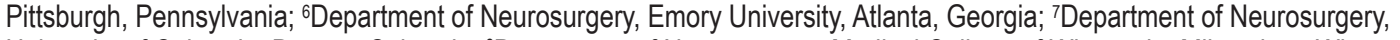
University of Colorado, Denver, Colorado; ${ }^{8}$ Department of Neurosurgery, Medical College of Wisconsin, Milwaukee, Wisconsin; ${ }^{9}$ Department of Neurosurgery, University of Wisconsin, Madison, Wisconsin; ${ }^{10}$ Department of Neurosurgery, Barrow Neurological Institute, Phoenix, Arizona; ${ }^{11}$ Section of Neurosurgery, University of Chicago, Chicago, Illinois; ${ }^{2}$ Department of Neurosurgery, Stanford University, Palo Alto, California; ${ }^{13}$ Department of Neurosurgery, University of California at San Francisco, San Francisco, California; ${ }^{14}$ Department of Neurosurgery, University of Illinois, Chicago, Illinois; ${ }^{15}$ Department of Neurosurgery, University of Ottawa, Ottawa, Ontario, Canada; ${ }^{16}$ Department of Neurosurgery, Mayo Clinic, Rochester, Minnesota; and ${ }^{17}$ Department of Neurosurgery, Baylor College of Medicine, Houston, Texas

OBJECTIVE In children, the repair of skull defects arising from decompressive craniectomy presents a unique set of challenges. Single-center studies have identified different risk factors for the common complications of cranioplasty resorption and infection. The goal of the present study was to determine the risk factors for bone resorption and infection after pediatric cranioplasty.

METHODS The authors conducted a multicenter retrospective case study that included all patients who underwent cranioplasty to correct a skull defect arising from a decompressive craniectomy at 13 centers between 2000 and 2011 and were less than 19 years old at the time of cranioplasty. Prior systematic review of the literature along with expert opinion guided the selection of variables to be collected. These included: indication for craniectomy; history of abusive head trauma; method of bone storage; method of bone fixation; use of drains; size of bone graft; presence of other implants, including ventriculoperitoneal (VP) shunt; presence of fluid collections; age at craniectomy; and time between craniectomy and cranioplasty.

RESULTS A total of 359 patients met the inclusion criteria. The patients' mean age was 8.4 years, and $51.5 \%$ were female. Thirty-eight cases (10.5\%) were complicated by infection. In multivariate analysis, presence of a cranial implant (primarily VP shunt) (OR 2.41, 95\% Cl 1.17-4.98), presence of gastrostomy (OR 2.44, 95\% Cl 1.03-5.79), and ventilator dependence (OR 8.45, 95\% CI 1.10-65.08) were significant risk factors for cranioplasty infection. No other variable was associated with infection.

Of the 240 patients who underwent a cranioplasty with bone graft, $21.7 \%$ showed bone resorption significant enough to warrant repeat surgical intervention. The most important predictor of cranioplasty bone resorption was age at the time of cranioplasty. For every month of increased age the risk of bone flap resorption decreased by $1 \%(\mathrm{OR} 0.99,95 \% \mathrm{Cl}$ $0.98-0.99, p<0.001)$. Other risk factors for resorption in multivariate models were the use of external ventricular drains and lumbar shunts.

ABBREVIATIONS $\mathrm{Cl}=$ confidence interval; $\mathrm{EVD}=$ external ventricular drain; $\mathrm{OR}=$ odds ratio; $\mathrm{VP}=$ ventriculoperitoneal. ACCOMPANYING EDITORIAL See pp 223-224. DOI: 10.3171/2018.4.PEDS18184.

SUBMITTED December 12, 2017. ACCEPTED March 19, 2018.

INCLUDE WHEN CITING Published online June 8, 2018; DOI: 10.3171/2018.3.PEDS17234. 
CONCLUSIONS This is the largest study of pediatric cranioplasty outcomes performed to date. Analysis included variables found to be significant in previous retrospective reports. Presence of a cranial implant such as VP shunt is the most significant risk factor for cranioplasty infection, whereas younger age at cranioplasty is the dominant risk factor for bone resorption.

https://thejns.org/doi/abs/10.3171/2018.3.PEDS17234

KEYWORDS cranioplasty; complication; infection; bone resorption; trauma

$\mathrm{D}$ ECOMPRESSIVE craniectomy is a relatively common procedure performed for treatment of a mass lesion such as a subdural hematoma or as part of a strategy to mitigate the damage from elevated intracranial pressure that can occur after trauma, stroke, or other brain insult. Patients who survive the initial injury and acute illness are left with a cranial defect. Cranioplasty is then required to avoid the physiological disturbances that may result from a cranial defect and for cosmesis..$^{5,9,14}$

In children, cranioplasty is associated with high rates of bone resorption and surgical site infection. A systematic review of published series of pediatric cranioplasty revealed an overall rate of bone resorption of $36 \%$ and an infection rate of $8 \% .{ }^{13}$ Although the infection rate is similar to the published rate observed in adults, bone resorption is more commonly encountered in children. ${ }^{16}$

Studies from single centers have suggested that variables such as time between craniectomy and cranioplasty, patient age, and size of bony defect may influence the likelihood of cranioplasty complication..$^{1-6,8,10-12,15}$ However, combined analysis of these studies has revealed no statistically significant effect of any of the variables for which pooled analysis was possible. ${ }^{13}$ The purpose of the present study, therefore, was to perform a large, multicenter, retrospective review of pediatric patients who had undergone cranioplasty after decompressive craniectomy to determine what factors are associated with bone resorption and with infection.

\section{Methods}

Thirteen participating centers identified potential subjects using existing trauma registries and neurosurgical case logs. All patients under 19 years who were undergoing first-time cranioplasty for reconstruction of a cranial defect between 2000 and 2011 were included, with the exception of those whose craniectomy and cranioplasty were performed at the same time. In other words, only patients who were undergoing their first operation for repair of a cranial defect were included, and patients who underwent bone removal and replacement in the same operation, such as craniofacial reconstruction, were excluded.

We studied 2 primary endpoints: cranioplasty infection and bone resorption. We defined cranioplasty infection as the surgical removal of the cranioplasty material coupled with use of antibiotic therapy (e.g., a patient with drainage from his or her incision treated with antibiotics alone and without removal of the cranioplasty material would not be considered to have had an infection). Bone resorption was defined as any secondary surgical procedure to augment the initial cranioplasty. Use of surgical definitions for these endpoints was chosen to minimize ambiguity.

Based on examination of the existing literature, as well as consensus opinion of the investigators, we selected the following data points to collect: age at the time of craniectomy, indication for craniectomy, history of nonaccidental trauma, greatest linear dimension of cranial defect, storage method for autologous bone, time between craniectomy and cranioplasty, method of cranioplasty material fixation (plates, sutures, etc.), cranioplasty material, presence of hydrocephalus, presence of subgaleal fluid collections, presence of cranial implants (ventriculoperitoneal [VP] shunt, subdural shunt, or other), and presence of comorbid medical conditions.

The target sample size was 300 patients. This number of included subjects would be sufficient to allow for detection of the observed differences in infection and resorption rates in all of the studies included in the systematic review noted above (with alpha $<0.05$ and beta $>0.8$ ). ${ }^{13}$ This sample size would also be sufficiently large to allow for detection of a difference of the magnitude observed by Inamasu et al. in their study of adult cranioplasty infection (5.1\% when the bone flap was preserved in a subcutaneous pocket vs $16.1 \%$ when frozen).

- Bone flap resorption. Resorption rates of $15 \%$ and $44 \%$, respectively, were seen in early ( $<6$ weeks) and late $(>$ 6 weeks) cranioplasty. ${ }^{10}$ Sample size needed with power $=0.8$ : 45 patients per group.

- Cranioplasty infection. Rates of postcranioplasty infection in adult patients from subcutaneous pockets and cryopreservation were $5.1 \%$ and $16.1 \%$, respectively? Sample size needed with power $=0.8: 139$ patients per group.

The statistical significance of differences between each endpoint of interest and continuous predictors was tested using 2-sample independent t-tests, with the KruskalWallis rank test employed for nonnormally distributed variables. The chi-square test (or Fisher exact test when assumptions were not met) was used to test association between categorical variables and the endpoint of interest. Univariate logistic regression with a threshold probability of $0.2+$ utilized to identify independent associations between predictors and each endpoint for initial inclusion in multivariate models. Multivariate logistic regression was employed to evaluate the best combination of predictors of the endpoints under study, with final model results reported as adjusted odds ratios (ORs) with $95 \%$ confidence intervals (CIs). Statistical significance was defined as $p<0.05$.

When considering the infection endpoint, all cases were included. However, when considering the resorption endpoint, only those patients who underwent cranioplasty with a material that might be resorbed were included in the analysis (i.e., patients who had titanium, methyl methacrylate, or PEEK cranioplasty were not included). In addition, patients whose cranioplasties were removed for infection 


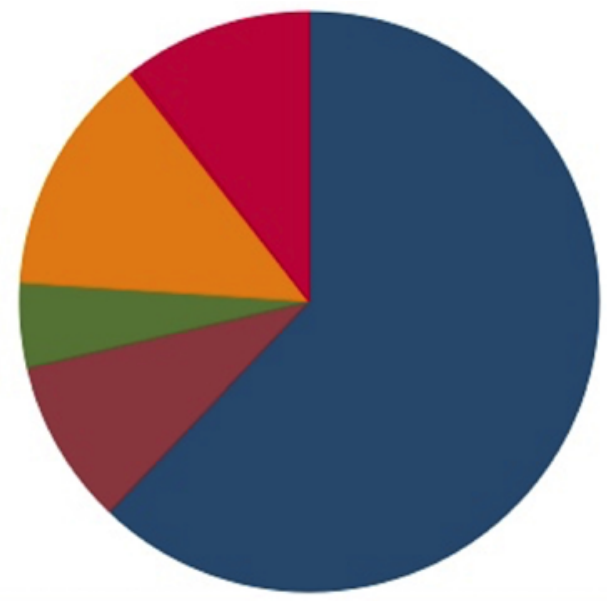

\begin{tabular}{|l|l|}
\hline $\begin{array}{l}\text { closed head trauma } \\
\text { ischemic stroke } \\
\text { other }\end{array}$ & $\begin{array}{l}\text { open head trauma } \\
\text { vascular, hemorrhage }\end{array}$ \\
\hline
\end{tabular}

FIG. 1. Etiology of initial injury that resulted in craniectomy. Figure is available in color online only.

were excluded from the resorption analysis, as these patients no longer had cranioplasty material in place to resorb. Statistical analysis was performed using SPSS version 22 (IBM Corp.) and SAS version 9.3 (SAS Institute).

\section{Results}

Participating centers identified a total of 359 patients who met the inclusion criteria. The average number of patients included in the study per center was 28 (range 5-61). The patients' mean age was $8.4 \pm 5.7$ years, and $51.5 \%$ were female. The mean duration of follow-up after cranioplasty was 32 months. Figure 1 illustrates the indications for initial craniectomy. Blunt traumatic brain injury without open skull fracture accounted for the majority of cases $(62 \%)$. Nonaccidental or abusive head trauma was the etiology in $12.5 \%$ of cases.

\section{Infection}

Of 359 total cases, there were 38 cases of cranioplasty infection, for an overall infection rate of $10.5 \%$. Univariate logistic regression analysis revealed that presence of a cranial implant (OR 2.62, 95\% CI 1.29-5.30), a VP shunt (OR $2.69,95 \%$ CI 1.29-6.00), a gastrostomy tube (OR 2.90, 95\% CI 1.26-6.69), and ventilator dependent status (OR $8.87,95 \%$ CI 1.21-64.87) were statistically significant predictors of cranioplasty infection. However, there was no statistically significant association between cranioplasty infection and indication for craniectomy, presence of nonaccidental trauma, age at cranioplasty, time between craniectomy and cranioplasty, size of the cranial defect, method of securing cranioplasty, material used for cranioplasty, use of surgical drain, presence of subgaleal fluid collection, or study site. Considering only those cases in which stored autograft bone was used, the method of bone storage also had no association with infection $(\mathrm{p}=0.45)$. See Table 1 for details.
TABLE 1. Univariate logistic regression predicting presence of infection $(n=359)$

\begin{tabular}{lccc}
\hline \multicolumn{1}{c}{ Variable } & OR & $95 \% \mathrm{Cl}$ & $\mathrm{p} \mathrm{Value}$ \\
\hline Nonaccidental trauma & 0.83 & $0.28-2.47$ & 0.74 \\
\hline Age at cranioplasty in mos & 1.00 & $1.00-1.01$ & 0.46 \\
\hline Time btwn craniotomy \& cranioplasty & 1.01 & $0.98-1.03$ & 0.53 \\
\hline Greatest linear dimension & 1.05 & $0.94-1.16$ & 0.40 \\
\hline No drain use & 0.67 & $0.34-1.32$ & 0.25 \\
\hline EVD use & 0.72 & $0.16-3.18$ & 0.67 \\
\hline Cranial implant & 2.62 & $1.29-5.30$ & 0.008 \\
\hline VP shunt & 2.69 & $1.29-6.00$ & 0.01 \\
\hline Bone storage in abdomen & 1.85 & $0.38-9.09$ & 0.45 \\
\hline Comorbidities & & & \\
\hline No comorbidity & 0.73 & $0.36-1.46$ & 0.37 \\
\hline Gastrostomy & 2.90 & $1.26-6.69$ & 0.01 \\
\hline Tracheostomy & 2.28 & $0.80-6.48$ & 0.12 \\
\hline Ventilator dependent & 8.87 & $1.21-64.87$ & 0.03 \\
\hline Spasticity & 1.39 & $0.46-4.24$ & 0.56 \\
\hline Spinal cord injury & 2.78 & $0.03-259.60$ & 0.66 \\
\hline
\end{tabular}

Boldface type indicates statistical significance at $p<0.05$.

The final multivariate model was created (and confirmed by backward elimination) with consideration of all variables with $\mathrm{p}<0.2$ on univariate analysis. Both presence of cranial implant and presence of VP shunt met this inclusion criterion. However, since cranial implant included VP shunt, subdural shunt, and "other" implant, and since 65 of 79 patients with a cranial implant had a VP shunt, it was anticipated that these variables would contribute statistically similar information to the model. Not surprisingly, collinearity diagnostics indicated weak multicollinearity between the 2 variables. Since the variable denoting presence of a cranial implant proved to be a stronger predictor than VP shunt in the univariate model, the variable representing cranial implant was chosen for inclusion in the multivariate model. The final multivariate model selected for prediction of cranial infection included presence of a cranial implant (OR 2.41,95\% CI 1.17-4.98), presence of gastrostomy (OR 2.44, 95\% CI 1.03-5.79), and ventilator dependent status (OR 8.45, 95\% CI 1.10-65.08) (Table 2).

\section{Resorption}

To assess variables for an association with bone resorption, only those patients who underwent cranioplasty with

TABLE 2. Multivariate logistic regression model predicting presence of infection $(n=359)$

\begin{tabular}{lccc}
\hline \multicolumn{1}{c}{ Variable } & OR & $95 \% \mathrm{Cl}$ & p Value \\
\hline Cranial implant & 2.41 & $1.17-4.98$ & $\mathbf{0 . 0 1 7}$ \\
\hline Gastrostomy & 2.44 & $1.03-5.79$ & $\mathbf{0 . 0 4 3}$ \\
\hline Ventilator dependent & 8.45 & $1.10-65.08$ & $\mathbf{0 . 0 4 0}$ \\
\hline
\end{tabular}

Boldface type indicates statistical significance at $p<0.05$. 
TABLE 3. Univariate logistic regression predicting bone resorption $(n=240)$

\begin{tabular}{|c|c|c|c|c|c|}
\hline \multirow[b]{2}{*}{ Variable } & \multirow[b]{2}{*}{ OR } & \multirow[b]{2}{*}{$95 \% \mathrm{Cl}$} & \multirow[b]{2}{*}{$p$ Value } & \multicolumn{2}{|c|}{ Type 3 Analysis of Effects } \\
\hline & & & & Wald $\chi^{2}$ & $p$ Value \\
\hline Nonaccidental trauma & 1.78 & $0.81-3.94$ & 0.15 & & \\
\hline Age at cranioplasty in mos & 0.99 & $0.98-0.99$ & $<0.0001$ & & \\
\hline Time btwn craniotomy \& cranioplasty & 0.97 & $0.90-1.04$ & 0.35 & & \\
\hline Greatest linear dimension & 1.05 & $0.95-1.15$ & 0.38 & & \\
\hline No drain use & 1.09 & $0.58-2.04$ & 0.80 & & \\
\hline EVD use & 2.82 & $1.13-7.02$ & 0.03 & & \\
\hline Cranial implant & 1.08 & $0.52-2.24$ & 0.85 & & \\
\hline VP shunt & 0.88 & $0.40-1.98$ & 0.76 & & \\
\hline Lumbar shunt & 8.84 & $1.02-76.80$ & 0.05 & & \\
\hline \multicolumn{6}{|l|}{ Comorbidities } \\
\hline No comorbidity & 1.46 & $0.79-2.70$ & 0.23 & & \\
\hline Gastrostomy & 0.80 & $0.29-2.23$ & 0.67 & & \\
\hline Tracheostomy & 0.46 & $0.10-2.09$ & 0.32 & & \\
\hline Ventilator dependent & 0.71 & $0.02-29.65$ & 0.86 & & \\
\hline Spasticity & 0.62 & $0.17-2.19$ & 0.45 & & \\
\hline Spinal cord injury & 10.97 & 0.12 to $>999.9$ & 0.30 & & \\
\hline Reason for craniotomy & & & & 0.4076 & 1.0 \\
\hline Closed head injury & Ref & Ref & Ref & & \\
\hline Open head injury & 0.74 & $0.21-2.59$ & 0.64 & & \\
\hline Ischemic stroke & 0.71 & $0.16-3.10$ & 0.65 & & \\
\hline Rupture of vascular lesion & 0.92 & $0.39-2.16$ & 0.84 & & \\
\hline Metabolic abnormality & 1.10 & $0.01-102.68$ & 0.97 & & \\
\hline Other & 0.95 & $0.30-2.98$ & 0.93 & & \\
\hline Method of bone flap storage & & & & 2.7601 & 0.25 \\
\hline Frozen & Ref & Ref & Ref & & \\
\hline Abdominal pocket & 0.211 & $0.01-4.57$ & 0.32 & & \\
\hline No stored bone & 0.39 & $0.10-1.53$ & 0.18 & & \\
\hline Method of bone flap fixation & & & & 8.5055 & 0.04 \\
\hline Suture & 3.32 & $1.29-8.54$ & 0.01 & & \\
\hline Titanium plates & Ref & Ref & Ref & & \\
\hline Resorbable plates & 2.20 & $1.07-4.49$ & 0.03 & & \\
\hline Other & 1.72 & $0.32-9.05$ & 0.52 & & \\
\hline Material & & & & 2.8128 & 0.25 \\
\hline Stored bone & Ref & Ref & Ref & & \\
\hline Other autograft & 0.34 & $0.08-1.51$ & 0.16 & & \\
\hline Allograft bone & 3.41 & $0.21-55.49$ & 0.39 & & \\
\hline Subgaleal fluid* & & & & 1.2563 & 0.74 \\
\hline None & Ref & Ref & Ref & & \\
\hline Present before cranioplasty & 0.82 & $0.22-3.07$ & 0.76 & & \\
\hline Present after cranioplasty & 0.71 & $0.15-3.42$ & 0.67 & & \\
\hline Present before/after cranioplasty & 1.63 & $0.57-4.68$ & 0.36 & & \\
\hline Study site & & & & 23.8229 & 0.02 \\
\hline $1(n=40)$ & Ref & Ref & Ref & & \\
\hline $2(n=6)$ & 8.04 & $1.26-51.26$ & 0.03 & & \\
\hline $3(n=20)$ & 1.59 & $0.44-5.70$ & 0.48 & & \\
\hline $4(n=30)$ & 1.43 & $0.45-4.54$ & 0.55 & & \\
\hline $5(n=8)$ & 0.26 & $0.01-6.01$ & 0.40 & & \\
\hline $6(n=20)$ & 0.34 & $0.05-2.25$ & 0.27 & & \\
\hline
\end{tabular}


» CONTINUED FROM PAGE 228

TABLE 3. Univariate logistic regression predicting bone resorption $(n=240)$

\begin{tabular}{cccccc}
\hline & & & & \multicolumn{2}{c}{ Type 3 Analysis of Effects } \\
\cline { 5 - 6 } Variable & OR & $95 \% \mathrm{Cl}$ & $\mathrm{p}$ Value & Wald $\chi^{2}$ & $\mathrm{p}$ Value \\
\hline Study site (continued) & & & & 23.8229 & $\mathbf{0 . 0 2}$ \\
\hline $7(n=12)$ & 1.65 & $0.37-7.42$ & 0.52 & \\
\hline $8(n=25)$ & 0.27 & $0.04-1.762$ & 0.17 & \\
\hline $9(n=3)$ & 2.68 & $0.23-31.73$ & 0.43 & \\
\hline $10(n=11)$ & 0.64 & $0.09-4.52$ & 0.65 & \\
\hline $11(n=43)$ & 1.40 & $0.48-4.06$ & 0.54 & \\
\hline $12(n=6)$ & 2.48 & $0.39-15.82$ & 0.34 & \\
\hline $13(n=16)$ & 7.22 & $1.99-26.16$ & 0.003 & \\
\hline
\end{tabular}

Ref $=$ reference.

Boldface type indicates statistical significance at $p<0.05$.

* Values for subgaleal fluid were missing in 66 cases.

a material that might be resorbed were evaluated. In addition, patients with documented infection were excluded from analysis of bone resorption, resulting in 240 patients retained for evaluation (216 who underwent cranioplasty with stored cranial autograft, 22 with other autograft, 2 with allograft bone). There were 52 cases of bone resorption (overall resorption rate 21.7\%). Age (in months) at time of cranioplasty (OR 0.99, 95\% CI 0.98-0.99) and external ventricular drain (EVD) use (OR 2.82, 95\% CI 1.13-7.02) showed significant association with bone resorption by univariate logistic regression (Table 3). Similarly, the odds of resorption were higher when cranioplasty fixation was performed with suture or resorbable plates as compared to titanium plates $(\mathrm{p}=0.04)$. There was also a significant association with study site, with 2 sites showing significantly higher odds ratios for bone resorption $(p=0.02)$ (Table 3$)$.

We attempted to construct a multivariate logistic regression model including all variables from the univariate analysis with $\mathrm{p}<0.2$. However, analysis of variables for lumbar shunt, bone flap fixation method, and study site was limited by small-sample event numbers and quasiseparation of data points when calculating maximum likelihood ratios. Therefore, no model could be built that included all of these variables. Using Firth's penalized likelihood estimation method to build multivariate models that included various combinations of the variables having a $p$ value $<0.2,14$ multivariate models were constructed (Table 4). In all of the models, age at the time of cranioplasty consistently remained statistically significant (OR 0.99, 95\% CI 0.98-0.99), indicating a $1 \%$ decrease in the risk of resorption for each month of increasing age. EVD use and lumbar shunt also proved to be significant or nearly significant in all models, but with wide confidence intervals, as expected given the small event numbers.

Because of the significant association of study site with bone resorption, we attempted to control for the "center effect" using multivariate modeling. However, because of the quasi-separation of data points noted above, creation of a stable model that included both lumbar shunt and study site was not possible. A model including study site and EVD use along with age at time of cranioplasty showed all predictors to be statistically significant (model 14 in Table 4). However, in this model only 2 study sites showed a significant association with bone resorption, both of which contributed a relatively small number of patients, as indicated by wide confidence intervals with a lower limit approaching 1.0 (site $2: \mathrm{n}=6$, OR $10.57,95 \%$ CI 1.53-73.06; and site $13: \mathrm{n}=16$, OR $6.90,95 \%$ CI 1.74-27.28).

\section{Discussion}

Cranioplasty for repair of a cranial defect in children is associated with a number of important complications. Despite several single-center studies and a systematic review/ meta-analysis, no definitive conclusions could be drawn about risk factors for the commonly occurring complications of infection and bone resorption..$^{13}$ The present study is a collaborative effort involving multiple investigators from 13 institutions to determine the risk factors that affect the occurrence of these complications.

\section{Infection}

We report an infection rate of $10.5 \%$ associated with cranioplasty in the pediatric population. This is similar to previously published infection rates from studies examining both adult and pediatric cohorts. ${ }^{13}$ Based on a single study of adult patients, one hypothesis was that storage of autologous cranium in the abdomen might lead to a lower infection rate than frozen storage. ${ }^{7}$ In the over 350 cranioplasty patients included, 288 cranioplasties involved autologous bone that had been either frozen (276) or stored in the patient's abdomen (12). There was no relationship between bone storage method and cranioplasty infection. In addition, contrary to the findings of several previously published single-center studies, the material used for cranioplasty was not associated with cranioplasty infection. ${ }^{16}$

Instead, we show that significant risk factors for cranioplasty infection include the presence of a cranial implant such as a VP shunt, the presence of a gastrostomy, and the requirement for mechanical ventilation. These findings might be a persuasive reason to consider performing cranioplasty operations before shunt or gastrostomy 
TABLE 4. Multivariate logistic regression predicting bone resorption $(n=240)$ using Firth penalized likelihood estimation

\begin{tabular}{|c|c|c|c|c|c|c|}
\hline \multirow{2}{*}{$\begin{array}{l}\text { Model } \\
\text { No. }\end{array}$} & \multirow[b]{2}{*}{ Model } & \multicolumn{2}{|c|}{ Max Likelihood Estimates } & \multirow[b]{2}{*}{$\mathrm{OR}(95 \% \mathrm{Cl})$} & \multirow{2}{*}{$\begin{array}{l}\text { Model Fit } \\
(\text { AIC })^{*}\end{array}$} & \multirow{2}{*}{$\begin{array}{l}\text { No. of } \\
\text { Obs }\end{array}$} \\
\hline & & Wald $\chi^{2}$ & $p$ Value & & & \\
\hline \multirow[t]{2}{*}{1} & Age at cranioplasty in mos & 19.2778 & $<0.0001$ & $0.99(0.98-0.99)$ & 212.974 & 236 \\
\hline & Method bone flap fixation & 0.2281 & 0.84 & $0.96(0.61-1.49)$ & & \\
\hline \multirow[t]{2}{*}{2} & Age at cranioplasty in mos & 18.2478 & $<0.0001$ & $0.99(0.98-0.99)$ & 213.123 & 240 \\
\hline & EVD use & 4.2503 & 0.04 & $2.79(1.05-7.41)$ & & \\
\hline \multirow[t]{2}{*}{3} & Age at cranioplasty in mos & 18.7116 & $<0.0001$ & $0.99(0.98-0.99)$ & 213.435 & 240 \\
\hline & Lumbar shunt & 4.1520 & 0.04 & $12.32(1.10-138.01)$ & & \\
\hline \multirow[t]{2}{*}{4} & Age at cranioplasty in mos & 19.4921 & $<0.0001$ & $0.99(0.98-0.99)$ & 201.351 & 228 \\
\hline & Nonaccidental trauma & 1.2991 & 0.25 & $0.59(0.24-1.46)$ & & \\
\hline \multirow[t]{2}{*}{5} & EVD use & 4.8476 & 0.03 & $2.79(1.12-6.97)$ & 242.313 & 236 \\
\hline & Method bone flap fixation & 0.1533 & 0.70 & $1.10(0.68-1.77)$ & & \\
\hline \multirow[t]{2}{*}{6} & EVD use & 4.4157 & 0.04 & $2.70(1.07-6.84)$ & 242.671 & 240 \\
\hline & Lumbar shunt & 3.4604 & 0.06 & $8.05(0.89-72.42)$ & & \\
\hline \multirow[t]{2}{*}{7} & Nonaccidental trauma & 2.6531 & 0.10 & $1.95(0.87-4.36)$ & 227.926 & 228 \\
\hline & EVD use & 6.9878 & 0.008 & $3.63(1.40-9.42)$ & & \\
\hline \multirow[t]{2}{*}{8} & Nonaccidental trauma & 2.7105 & 0.10 & $1.95(0.88-4.32)$ & 230.361 & 228 \\
\hline & Lumbar shunt & 4.3614 & 0.04 & $10.09(1.15-88.39)$ & & \\
\hline \multirow[t]{3}{*}{9} & Age at cranioplasty in mos & 18.6328 & $<0.0001$ & $0.99(0.98-.99)$ & 208.314 & 236 \\
\hline & EVD use & 3.6072 & 0.0575 & $2.65(0.97-7.23)$ & & \\
\hline & Lumbar shunt & 3.9317 & 0.047 & $12.60(1.03-154.21)$ & & \\
\hline \multirow[t]{3}{*}{10} & Age at cranioplasty in mos & 12.1290 & 0.0005 & $0.99(0.98-0.99)$ & 232.52 & 236 \\
\hline & Method bone flap fixation & 1.0108 & 0.80 & $0.98(0.62-1.55)$ & & \\
\hline & EVD use & 4.5827 & 0.03 & $3.01(1.10-8.28)$ & & \\
\hline \multirow[t]{3}{*}{11} & Backward elimination*_EVD used removed & & & & & \\
\hline & Age at cranioplasty in mos & 19.2438 & $<0.0001$ & $0.99(0.98-0.99)$ & 225.8570 & 238 \\
\hline & Lumbar shunt & 4.6300 & 0.03 & $15.97(1.28-199.31)$ & & \\
\hline \multirow[t]{4}{*}{12} & Backward elimination*_nonaccidental trauma \& study site removed & & & & 209.922 & 226 \\
\hline & Age at cranioplasty in mos & 19.7058 & $<0.0001$ & $0.99(0.98-0.99)$ & & \\
\hline & EVD use & 5.4810 & 0.02 & $3.57(1.23-10.38)$ & & \\
\hline & Lumbar shunt & 4.4165 & 0.04 & $16.75(1.21-231.97)$ & & \\
\hline \multirow[t]{4}{*}{13} & $\begin{array}{l}\text { Backward elimination*-material, bone flap method fix, nonaccidental } \\
\text { trauma, no comorbidity, \& study site removed }\end{array}$ & & & & & \\
\hline & Age at cranioplasty in mos & 19.8488 & $<0.0001$ & $0.99(0.98-0.99)$ & 209.218 & 225 \\
\hline & EVD use & 5.4027 & 0.02 & $3.55(1.22-10.33)$ & & \\
\hline & Lumbar shunt & 4.4004 & 0.04 & $16.75(1.20-233.06)$ & & \\
\hline \multirow[t]{14}{*}{14} & Age at cranioplasty in mos & 17.4346 & $<0.0001$ & $0.99(0.98-0.99)$ & 199.602 & 240 \\
\hline & EVD use & 3.9990 & 0.045 & $3.74(1.03-13.63)$ & & \\
\hline & Study site & 22.7134 & 0.03 & & & \\
\hline & $1(n=40)$ & Ref & Ref & Ref & & \\
\hline & $2(n=6)$ & 5.7159 & 0.02 & $10.57(1.53-73.06)$ & & \\
\hline & $3(n=20)$ & 0.4651 & 0.50 & $1.63(0.40-6.59)$ & & \\
\hline & $4(n=30)$ & 1.3066 & 0.25 & $2.06(0.60-7.11)$ & & \\
\hline & $5(n=8)$ & 0.8215 & 0.36 & $0.23(0.01-5.45)$ & & \\
\hline & $6(n=20)$ & 0.6241 & 0.43 & $0.46(0.07-3.20)$ & & \\
\hline & $7(n=12)$ & 0.1234 & 0.73 & $0.72(0.12-4.51)$ & & \\
\hline & $8(n=25)$ & 2.2467 & 0.13 & $0.22(0.03-1.58)$ & & \\
\hline & $9(n=3)$ & 0.0927 & 0.76 & $1.48(0.12-18.21)$ & & \\
\hline & $10(n=11)$ & 0.1341 & 0.71 & $0.68(0.09-5.34)$ & & \\
\hline & $11(n=43)$ & 0.7201 & 0.40 & $1.64(0.53-5.09)$ & & \\
\hline
\end{tabular}


TABLE 4. Multivariate logistic regression predicting bone resorption $(n=240)$ using Firth penalized likelihood estimation

\begin{tabular}{|c|c|c|c|c|c|c|}
\hline \multirow{2}{*}{$\begin{array}{l}\text { Model } \\
\text { No. }\end{array}$} & \multirow[b]{2}{*}{ Model } & \multicolumn{2}{|c|}{ Max Likelihood Estimates } & \multirow[b]{2}{*}{ OR $(95 \% \mathrm{Cl})$} & \multirow{2}{*}{$\begin{array}{l}\text { Model Fit } \\
(\mathrm{AIC})^{*}\end{array}$} & \multirow{2}{*}{$\begin{array}{c}\text { No. of } \\
\text { Obs }\end{array}$} \\
\hline & & Wald $\chi^{2}$ & $p$ Value & & & \\
\hline \multicolumn{7}{|c|}{14 (continued) } \\
\hline & & 1.1249 & 0.29 & $2.91(0.40-21.00)$ & & \\
\hline & & 7.5715 & 0.01 & $6.90(1.74-27.28)$ & & \\
\hline
\end{tabular}

$\mathrm{AIC}=$ Aikake information criterion; $\max =$ maximum; obs = observations

Boldface type indicates statistical significance at $p<0.05$.

* AIC measures the amount of information that is lost when comparing one model to another. Higher AIC values indicate that more of the information was lost in construction of the model-i.e., lower values represent better "fit" of the data.

placement if this strategy is feasible for a given patient. Because of our limited ability to collect data across many sites, information about commonly discussed risk factors for infection such as preoperative surgical preparation details, perioperative antibiotics, use of double gloves, etc. are not available.

\section{Resorption}

Of the 240 patients who underwent a cranioplasty with bone, which was then at risk for resorption, $21.7 \%$ showed bone resorption significant enough to warrant repeat surgical intervention. This rate is similar to rates in previously published reports. ${ }^{13} \mathrm{We}$ found that the predominant risk factor for cranioplasty resorption is the age of the patient, with younger patients at higher risk than older ones. While the odds ratio of 0.99 seems like a small effect size, an odds ratio of 0.99 for a continuous variable such as age indicates that for each unit of change (i.e., 1 month older) the risk of resorption is $1 \%$ lower. While this relationship will likely break down at older ages, the current study includes only children, and thus this result is logical. Furthermore, the very narrow confidence interval indicates a high degree of certainty that this result fits the observations well.

Other factors that influenced risk of bone resorption are use of EVDs and lumbar shunts. These variables have much wider confidence intervals and smaller numbers of events upon which to base these conclusions and thus should be considered as less definitive risk factors. None of the variables that have previously been identified as potential risk factors for resorption (method of bone storage, time between craniectomy and cranioplasty, type of bone used [stored autograft, other autograft such as rib or adjacent calvaria, allograft bone], history of abusive head trauma, size of the cranial defect, and method of cranioplasty fixation) were statistically significant in the present study.

In light of these findings, a decision to use a manufactured prosthesis for younger children may be justified. These devices do not have the problem of resorption that is seen with autograft bone. In the present analysis, contrary to previous reports, they are not associated with a higher risk of infection. These implants may require future replacement if there is significant growth of the calvaria, but consideration of skull growth is beyond the scope of this work.

\section{Limitations}

This study represents a large multicenter retrospective review. While this allows for analysis of a large number of subjects, there are also limitations. There was no central review of imaging, so technique for measurement of the largest linear dimension of the cranial defect was not standardized. One person conducted the measurement at each site-often a neurosurgery resident. While this may lead to reduced precision of this measurement, the resulting analysis of both infection and resorption showed odds ratios close to 1.0 with relatively small confidence intervals that included 1.0. Therefore, despite this limitation, we are confident that there is little impact of defect size on risk for either of these outcomes.

The definition of bone resorption allows for some subjectivity. In order to standardize definition across multiple centers, we required that a surgical procedure be performed to correct the defect that resulted from bone resorption. Therefore, the treating surgeon's judgment is part of that outcome. This is a limitation of the study, but a stricter definition would not have been practical with this study methodology.

We included as many independent variables as possible for inclusion and analysis. It is possible that other factors play a role but were not analyzed. For example, the presence of a comminuted fracture has been identified as a risk factor. ${ }^{3}$ Because data collection was underway before that finding was published, comminuted fracture was not included. It is possible that other factors may similarly be missed.

\section{Conclusions}

Cranioplasty in children continues to carry a high risk of complication. The present study confirms previously observed rates of infection and bone resorption. In addition, in the largest study on this topic to date, we have shown that the presence of a cranial implant, such as a VP shunt, or gastrostomy increases the risk of cranioplasty infection. Bone resorption is most dependent on the age of the patient, with younger patients at higher risk for resorption.

\section{Acknowledgments}

We would like to acknowledge the assistance of these individu- 
als without whom this work would not have been possible: Hubert Lee, MD; Mohammed AlGhamdi, MD; Sarmad Al-Karawi, MD; and Sarah Graber.

\section{References}

1. Blair GA, Gordon DS, Simpson DA: Cranioplasty in children. Childs Brain 6:82-91, 1980

2. Blum KS, Schneider SJ, Rosenthal AD: Methyl methacrylate cranioplasty in children: long-term results. Pediatr Neurosurg 26:33-35, 1997

3. Bowers CA, Riva-Cambrin J, Hertzler DA II, Walker ML: Risk factors and rates of bone flap resorption in pediatric patients after decompressive craniectomy for traumatic brain injury. J Neurosurg Pediatr 11:526-532, 2013

4. Frassanito P, Massimi L, Caldarelli M, Tamburrini G, Di Rocco C: Complications of delayed cranial repair after decompressive craniectomy in children less than 1 year old. Acta Neurochir (Wien) 154:927-933, 2012

5. Grant GA, Jolley M, Ellenbogen RG, Roberts TS, Gruss JR, Loeser JD: Failure of autologous bone-assisted cranioplasty following decompressive craniectomy in children and adolescents. J Neurosurg 100 (2 Suppl Pediatrics):163-168, 2004

6. Gruber R, Peter R, Hora J: The prognosis of cranioplasty following large craniectomy in children. $\mathbf{Z}$ Kinderchir 43:375-383, 1988

7. Inamasu J, Kuramae T, Nakatsukasa M: Does difference in the storage method of bone flaps after decompressive craniectomy affect the incidence of surgical site infection after cranioplasty? Comparison between subcutaneous pocket and cryopreservation. J Trauma 68:183-187, 2010

8. Josan VA, Sgouros S, Walsh AR, Dover MS, Nishikawa H, Hockley AD: Cranioplasty in children. Childs Nerv Syst 21:200-204, 2005

9. Moreira-Gonzalez A, Jackson IT, Miyawaki T, Barakat K, DiNick V: Clinical outcome in cranioplasty: critical review in long-term follow-up. J Craniofac Surg 14:144-153, 2003

10. Piedra MP, Thompson EM, Selden NR, Ragel BT, Guillaume DJ: Optimal timing of autologous cranioplasty after decompressive craniectomy in children. J Neurosurg Pediatr 10:268-272, 2012

11. Pochon JP, Klöti J: Cranioplasty for acquired skull defects in children-a comparison between autologous material and methylmethacrylate 1974-1990. Eur J Pediatr Surg 1:199201, 1991

12. Posnick JC, Goldstein JA, Armstrong D, Rutka JT: Reconstruction of skull defects in children and adolescents by the use of fixed cranial bone grafts: long-term results. Neurosurgery 32:785-791, 1993

13. Rocque BG, Amancherla K, Lew SM, Lam S: Outcomes of cranioplasty following decompressive craniectomy in the pediatric population. J Neurosurg Pediatr 12:120-125, 2013

14. Schuss P, Vatter H, Marquardt G, Imöhl L, Ulrich CT, Seifert V, et al: Cranioplasty after decompressive craniectomy: the effect of timing on postoperative complications. J Neurotrauma 29:1090-1095, 2012

15. Taggard DA, Menezes AH: Successful use of rib grafts for cranioplasty in children. Pediatr Neurosurg 34:149-155, 2001

16. Yadla S, Campbell PG, Chitale R, Maltenfort MG, Jabbour P, Sharan AD: Effect of early surgery, material, and method of flap preservation on cranioplasty infections: a systematic review. Neurosurgery 68:1124-1130, 2011

\section{Disclosures}

The authors report no conflict of interest concerning the materials or methods used in this study or the findings specified in this paper.

\section{Author Contributions}

Conception and design: Rocque, Baird, Greene, Hankinson, Lew, Grant, Gupta, Auguste, Wetjen, Lam. Acquisition of data: Rocque, Thompson, Piedra, Baird, Selden, Greene, Deibert, Hankinson, Lew, Iskandar, Bragg, Frim, Grant, Gupta, Auguste, Nikas, Vassilyadi, Muh, Lam. Analysis and interpretation of data: Rocque, Agee, Lew, Lam. Drafting the article: Rocque, Agee, Greene, Lew, Lam. Critically revising the article: Rocque, Thompson, Baird, Greene, Lew, Grant, Gupta, Auguste, Vassilyadi, Muh, Wetjen, Lam. Reviewed submitted version of manuscript: Rocque, Agee, Thompson, Piedra, Baird, Greene, Deibert, Hankinson, Lew, Iskandar, Bragg, Frim, Grant, Gupta, Auguste, Nikas, Vassilyadi, Muh, Wetjen, Lam. Approved the final version of the manuscript on behalf of all authors: Rocque. Statistical analysis: Agee. Administrative/technical/material support: Rocque, Frim, Lam. Study supervision: Rocque, Lam.

\section{Supplemental Information \\ Previous Presentations}

This work was presented at the AANS/CNS Joint Section on Pediatric Neurosurgery, Amelia Island, FL, December 2014; and at the American Society of Pediatric Neurosurgery, Kona, HI, January 2015.

\section{Correspondence}

Brandon G. Rocque: University of Alabama at Birmingham, Birmingham, AL. brandon.rocque@childrensal.org. 